\title{
Geniposide Can Rescue the Erythropoiesis Inhibition Caused by Chemotherapy Drug 5-Fu
}

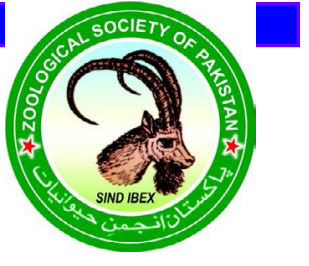

\author{
Hong-mei Gao, Wen-long Su, Gui-bin Tao, Han-yang Li, Wen-zheng Cao and \\ Zhi-dong Qiu* \\ Changchun University of Chinese Medicine, Changchun 130117, Jilin, China.
}

\begin{abstract}
A B S T RA C T
The action of erythropoietin will determined the red cell production. We know there are other regulatory factors, including molecules interact with cells, chemical, irradiation, it's in the bone marrow (BM). Most chemotherapy drugs are toxic to cancer cells and normal healthy hematopoietic cells. Hemoglobin and red blood cell levels drop in cancer patients treated with chemotherapy. Geniposide can reduce the adverse radiation damage of bloosd tissue after high dose irradiation. We found that geniposide can recovery the red blood count after chemotherapy medications (5-Fluorouracil, 5-FU) treatment mice. The mechanism of action of genistein on erythrocyte production is not clear. This study suggests that Geniposide promotes red blood cell production. We demonstrated that genistein did not affect the erythrocyte differentiation of mouse CD $34^{+}$cells. Then, we tested the geniposide indirectly affecting BM accessory cells. We conclude that geniposide maybe will control the erythropoiesis in vivo and reverse the BM microenvironmental signals, and this could provide an idea to attenuate anemia in chemotherapy.
\end{abstract}

Article Information
Received 12 September 2018
Revised 29 June 2019
Accepted 01 October 2019
Available online 05 March 2020
Authors' Contribution
H-mG Overall instructor. W-IS, G-bT
and H-yL performed the experiment.
W-zC, Z-dQ helped in experimental
work.
Key words
Geniposide, 5-Fluorouracil,
Erythropoiesis, Chemotherapy

\section{INTRODUCTION}

$\mathrm{T}$ here are lot of the chemotherapy medications used for cancer patients. During the chemotherapy, the chemotherapy medications are toxic to cancer cells. At the same time, they are hurting the healthy cells. It will be the serious chemotherapy side effects. There are several kinds of blood cell related chemotherapy side effects, including: anemia, neutropenia, thrombocytopenia (Carmeliet, 2005; Chen et al., 2010; Chen et al., 2017; Folkman, 2007). Pirker et al. reported that hemoglobin and red blood cell level will decline in cancer patients receiving chemotherapy (Chen et al, 2016). Fluorouracil, also known as 5-FU, acts as a thymidylate synthase (TS) inhibitor, chemotherapy drugs are used to treat different types of cancer (Henry, 2006). Shan et al. (2017) suggested that 5-FU anti-tumor effects through suppression of Akt signaling.

Geniposide, that is the appearance of brown to white crystalline powder, is from the madder plants gardenia dry and mature fruit extracted from a ring iridoid glycosides compounds. There are several papers introduced that geniposide has the protective effect on liver injury. Also, geniposide has the anti-inflammatory and other pharmacological effects (Lazar-Karsten et al., 2011). Shan et al. (2017) proved that geniposide has the ability to decrease undesirable radiation damage to

\footnotetext{
* Corresponding author: qzdcczy@163.com 0030-9923/2020/0003-1023 \$ 9.00/0

Copyright 2020 Zoological Society of Pakistan
}

the hematologic tissue after high dose irradiation (Longley et al., 2003). In our study, we found that geniposide can recovery the red blood count and hemoglobin level after the mice treatment by 5-FU. But the exact mechanisms by geniposide affect erythropoiesis remain unclear.

Vascular endothelial growth factor (VEGF) signaling pathway is crucial to human physiologic functions, and it is more important in conditions of cancer (Ma et al., 2009; Meng, 2013). Gardenia jasminoides could increase the VEGF mRNA and protein expressions. We know that 5-FU anti-tumor effects through suppression of Akt signaling pathway (Shan et al., 2017), and the VEGF in the Akt/ VEGF signaling pathway plays an important role (Pirker et al., 2013). Since geniposide binds VEGF, a putative red blood cell regulator, the experiment used a combination of geniposide and 5-fu.

Although the geniposide can recovery the red blood count and hemoglobin level after the mice treatment by 5-FU, we don't know the mechanism, yet. The geniposide can't increase the erythropoiesis directly. These findings suggest that this may be a more complex action by geniposide glycosides affecting erythrocyte production in the body. To understand these results, we tested the effect of geniposide on erythropoiesis in mice in vitro and in vivo.

\section{MATERIALS AND METHODS}

\section{Cell cultures}

From adult mouse bone marrow (BM), mouse peripheral blood $(\mathrm{PB}) \mathrm{CD}^{+} 4^{+}$cells, we generate the erythroid cells by using a two-step liquid culture system. 
Mouse $\mathrm{CD} 34^{+}$cells were purchased from Shanghai Suer Biological Technology Co., Ltd. To culture the cells using for hematopoietic colony assay, thawing the tube, CD34 ${ }^{+}$ cells were cultured in 10\% FBS Iscove modified Dulbecco culture medium (IMDM) for $24 \mathrm{~h}$, and then IMDM cells were replaced with $1 \%$ penicillin/streptomycin $(\mathrm{P} / \mathrm{S}) .1 \%$ L-Glutamine, $20 \mathrm{mmol} / \mathrm{L} \beta$-mercaptoethanol ( $\beta$-ME), 1\% bovine serum albumin (BSA) and 30\% BIT 9500 without passage.

\section{Analyses of mice}

Non-pathogenic SD mice aged 11 weeks were used, and the experimental procedures were provided by vita river experimental animal technology co., LTD. (Beijing, China, Animal license No.: SCXK Beijing 20160006.Animal Experimental Ethical Inspection Form of Changchun University of Chinese Medicine, Approval No.: 20180001). Animals were housed in laboratory facilities with a temperature range of 21.0 to $25.0^{\circ} \mathrm{C}$, relative humidity of 40.0 to $70.0 \%$, changes the air at least 15 times per hour, and 12 hours light / dark cycle. Four mice were placed in a cage and given a fixed formula pellet diet and filtered tap water.

After one week of acclimatization, the mice were randomly classified into 3 groups, with 4 mice in each group. Phosphate-buffered saline (PBS) solution dissolved $150 \mathrm{mg} / \mathrm{kg}$ of $5-\mathrm{FU}$ (Shandong Hualu Pharmaceutical Co., Ltd.), PBS solution dissolved $100 \mu \mathrm{g} / \mathrm{mL}$ Geniposide (China Pharmaceutical and Biological Products). The mice were examined in a cohort of control group $(n=4), 5-F U$ group $(n=4)$, and $5-\mathrm{FU}+$ geniposide group $(\mathrm{n}=4)$ mice. The control group are the 11-week-old male mice without injection; 5-FU group: 5-fluorouracil $(150 \mathrm{mg} / \mathrm{kg})$ was injected intravenously into 11 -week-old male mice for 15 days, once a day. The 5-Fu+ geniposide group was injected geniposide $(100 \mu \mathrm{g} / \mathrm{mL})$ intravenously every day $(0.5 \mathrm{~mL})$ for 7 days, then given geniposide and $(0.2 \mathrm{~mL})$ of $5-\mathrm{Fu}(150 \mathrm{mg} / \mathrm{kg})$ for 15 days at the same time once a day. Peripheral blood (PB) was collected from mice with postorbital hemorrhage, and smear was stained with May-Giemsa, and Hemavet System 950FS was performed.

After 15 days, blood was taken, the mice were euthanized, and the body was dissected. The organs were examined by colony analysis and FACS. For the histopathology analyses, we harvested the femurs and fixed in formaldehyde, after the decalcified, then do the paraffin embedded. Except for the step of decalcification spleens were treated same process. Sections were cut at $4.5 \mu \mathrm{m}$, and stained with $\mathrm{H}$ and $\mathrm{E}$.

\section{Hematopoietic colony assay}

Metho Cult system (Stem Cell Technologies) was used to detect the burst unit erythrocytes (BFU-Es) and cultured for 15 days before counting under an inverted microscope.

\section{Flow cytometric analysis}

Erythrocyte analysis was performed with CD71 and Ter119 staining of spleen or BM single-cell suspension (BD Bioscience), and then washed with $\mathrm{PBS} / 2 \% \mathrm{FBS}$. In the analysis of lineage-Sca ${ }^{+} \mathrm{c}-\mathrm{Kit}^{+}$(LSK) and progenitor population (lineage-Sca- $1^{-} \mathrm{c}-\mathrm{Kit}^{+}, \mathrm{LK}$ ) analysis, in the subsequent FACS analysis, nucleated BM cells were stained with CD71 and Ter119 to remove red blood cells. The cells were further stained with Fc RII/III, CD34, Sca-1 and c-Kit antibodies (BD Biosciences). In order to analyze LSK subsets, lineage-depleted (lineage-failure) cells were isolated using the lineage cell depletion kit (Miltenyi Biotec), then stained with Sca-1 (Biolegend), c-Kit, CD34 and Flt3 (eBioscience), and then stained with FACS. Using CyAnADPanalyzer (Beckman Coulter) to analyze flow cytometry. Flow Jo Version 10.4.1 (Tree Star) was used to analyze the data.

\section{Western blot analysis}

Cells or organs were lysed with pyrolysis liquid on the ice for $30 \mathrm{~min}$. The lysate was centrifuged at 12000 $\mathrm{xg}$ for $10 \mathrm{~min}$ at $4{ }^{\circ} \mathrm{C}$. The supernatant was collected and the protein concentration was determined by BCA protein kit (Beyotime, Jiangsu, China). SDS-PAGE was used to separate all the protein extracts from the tested samples and transfered to the PVDF membrane $(0.22 \mu \mathrm{m}$, Millipore, MA, USA). After blocking for 1 hour with 5\% skimmed milk, the PVDF membrane was incubated at $4{ }^{\circ} \mathrm{C}$ with primary antibodies overnight (PI3K 1:1000, p-PI3K 1:1000, Akt 1:1000, p-Akt 1:1000, and GAPDH 1:8000). All antibodies were obtained from Cellular Signaling Technologies (Danvers, MA, USA). The blot was rinsed with Tris buffer saline containing $0.1 \%$ TBST three times. ten minutes each time. Membranes were incubated with horseradish peroxidase (HRP)-conjugated secondary antibodies (Cell Signaling Technology, Danvers, MA, USA) at room temperature for $1 \mathrm{~h}$. After washing with TBST again, immunoreactivity of the membrane was determined by electrochemical luminescence system (ECL) (Thermo Fisher Scientific, MA, USA). The protein band density was measured using Image J (NIH image software) and normalized to the relevant controls.

\section{Reagents}

5-FU was purchased from Shandong Hualu Pharmaceutical Co., Ltd. Geniposide was purchased from 
China Pharmaceutical and Biological Products. Geniposide was detected at different concentrations of $5-1,000 \mathrm{mg} / \mathrm{mL}$.

\section{Statistical analysis}

One-way analysis of variance and Bonferroni post hoc tests was used to compare groups. GraphPad Prism 5.0 (GraphPad Software, Inc., La Jolla, CA, USA) was used to analyze all the data and images. $\mathrm{P}<0.05$ was considered to indicate a statistically significant difference.

\section{RESULTS}

\section{Genistein has effect on erythrocyte differentiation of CD34 cells}

To detect the effects of geniposide on $\mathrm{CD} 34^{+}$cells, the standard methylcellulose cultures were setup. The cultures containing stem cell factor (SCF), erythropoietin (EPO), and Il-3 in the serum-free conditions.

Figure 1A shows the BFU-E colony number formed from $\mathrm{BM}$ assay, or $\mathrm{PB}$ derived $\mathrm{CD} 34^{+}$cells at 50 and 100 $\mu \mathrm{mol} / \mathrm{mL}$ with or without geniposide (control). The results showed no significant difference between the two groups. The size and morphologic appearance of the BFU-E colonies were not affected by geniposide treatment.

We evaluated $\mathrm{CD} 34^{+}$cells in a two-step liquid culture system to elucidate the effect of geniposide on the ability of $\mathrm{CD}_{3} 4^{+}$cells to produce erythrocytes (Pronk et al., 2007). CD34+ $(\mathrm{N}=1.25$ 105) cells were cultured for 7 days in serum-free medium of EPO and SCF. The expression of CD71(transport receptor) and Ter 119 in the resulting cells was then analyzed by flow cytometry. We counted control cells and genistein treated cells and found that the number of living cells was similar (e.g., $4.2 \pm 1.9 \times 10^{5}$ in control group vs. $4.6 \pm 1.3 \times 10^{5}$ cells in geniposide treated group).

This indicated that geniposide has no effect on the proliferation capacity of $\mathrm{CD} 34+$ cells. The ratio of $\mathrm{CD} 71^{+}$ / Ter $119^{+}$cells was erythrocyte generating cells, and we found that there were $100 \mu \mathrm{g} / \mathrm{mL}$ of geniposide in the group compared with the control group (e.g., $71.62 \pm$ $11.2 \%$ in geniposide group vs. $69.34 \pm 5.7 \%$ in untreated group; $p=0.4194$; Fig. 1B). Our results led us to wonder whether genistein treatment might affect the maturation of red blood cells in culture. $\mathrm{CD} 34^{+}$cells were cultured for 7 days with or without $100 \mathrm{mg} / \mathrm{mL}$ geniposide in serum-free medium and cultured for 7 days. From the results shown in Figure 1C, we concluded that geniposide treatment did not affect end-stage erythrocyte differentiation, since similar number of Ter119 cells were generated with or without geniposide. These findings demonstrate that in vitro, geniposide does not affect the erythropoiesis directly.
Effect of CM from geniposide-treated BM cells on erythropoiesis

The hematologic parameters were examined in a cohort of control group $(n=4), 5$-FU group $(n=4)$, and 5 -FU + geniposide group $(\mathrm{n}=4)$ mice. The control groups are the 11-week-old male mice without injection. 5-FU group: 5-Fluorouracil $(150 \mathrm{mg} / \mathrm{kg})$ injected intravenously into 11-week-old male mice for 3, 7, 9, 12 and 15 days. 5-FU + geniposide group: firstly, geniposide was injected for 7 days and 3 days, respectively, then $5-\mathrm{FU}(150 \mathrm{mg} / \mathrm{kg})$ was injected intravenously into 11-week-old male mice for 3 days, 7 days; after that we injected geniposide $(100 \mu \mathrm{g} /$ $\mathrm{mL}$ ) intravenously for 9 days, 12 days and 15 days (Fig. 2A). At each time point, blood was drawn from the tail vein of the mice and an automatic blood count (Hemavet System 950FS) was done (Walenda et al., 2010).

The control group had no difference in red blood cell count and hemoglobin levels from day 0 to day 15 . The 5-FU group, the red blood cell counts and hemoglobin levels significantly decreased from day 3 to day 15 . But in the 5-FU + geniposide group, we can see that when we inject 5-FU, the number of red blood cells and the hemoglobin level decrease (Day 3, 5, 9) and the levels were recovered when we injected the geniposide (Day 12 and 15) (Fig. 2B). After 15 days, flow cytometric analyses were performed with spleen and BM cell preparations were made to characterize the cell surface epitopes on three groups. The BM and spleen contained predominant proportions of erythroblasts at various stages $\left(C D 71^{\text {hi }}\right.$ Ter119 ${ }^{\text {low }}$, R1, proerythroblasts; Ter $119^{\text {hi }} \mathrm{CD} 71^{\text {hi }}$, R2, basophilic erythroblast; Ter $119^{\text {hi }} \mathrm{CD} 71^{\text {med }}, \mathrm{R} 3$, late basophilic and polychromatophilic erythroblast and Ter119 ${ }^{\text {hi }} \mathrm{CD} 71^{\text {low }}$, R4, orthochromatophilic erythroblast; Fig. 3A, B).

To examine if the HSC/HPC cell population were altered in these 5-FU group mice or 5-FU + geniposide group mice, $\mathrm{BM}$ cells were subject to flow cytometric analysis with HSC/HPC cell markers as described previously (Rodgers et al., 2008). The proportion of LK cell population was $12.42 \pm 5.3 \%$ and the LSK cell population was $2.25 \pm 1.8 \%$ in the 5 -FU group mice or 5 -FU + geniposide group mice (LK was $26.69 \pm 5.9 \%$ and LSK was $2.91 \pm 2.2 \%$ ) compared with control group mice (LK was $28.34 \pm 7.2 \%$ and LSK was $2.39 \pm 2.1 \%$ ) (Fig. $3 \mathrm{C}, \mathrm{D})$.

Histology examination of $\mathrm{H}$ and $\mathrm{E}$ stained BM, spleen sections of control group, 5-FU group, and 5-FU + Geniposide group mice (Fig. 3E, F). It can be seen that in $\mathrm{BM}$, the 5-FU group had fewer nuclei of blood cells, and the number of cells was reduced, but the number of cells recovered after the drug was given. In spleen, 5-FU cells undergo fission, and the cells recover after the drug was given. 

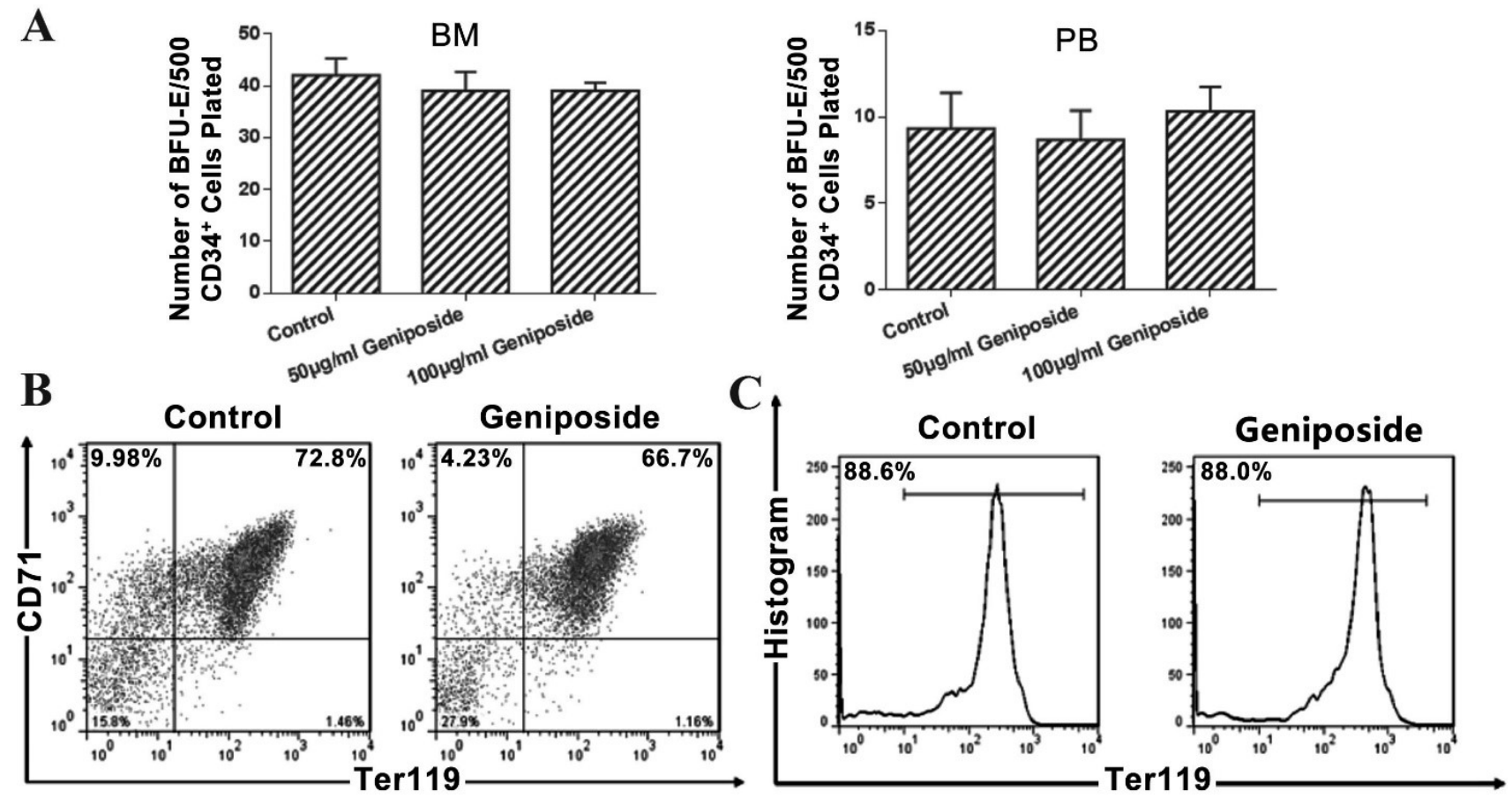

Fig. 1. Bar chart for the geniposide effects on erythroid differentiation. (A), BFU-E colonies assayed quantification from BM and $\mathrm{PB}$ derived $\mathrm{CD} 34+$ cells after 14 days incubation, $\mathrm{CD} 34+$ cells cultured in a methylcellulose-based culture supplemeted with SCF, EPO, and IL-3, including control group (absence Geniposide) or experiment group (pesence of Geniposide , 50 and $100 \mathrm{ug} /$ $\mathrm{ml}$ ); (B), flow cytometric analyses of cells expression CD71 and Ter119 generated from BM derived CD34+ cells incubated for 7 days in serum-free liquid culture system (IMDM-based media with SCF and EPO) in the control group (absence Geniposide) or experiment group (presence of Geniposide, $100 \mathrm{ug} / \mathrm{mL}$ ); (C), flow cytometry histograms of Ter119 expression of erythroid culture after 14 days in liquid culture in the control group (absence Geniposide) or experiment group (presence of Geniposide, 100ug/mL).

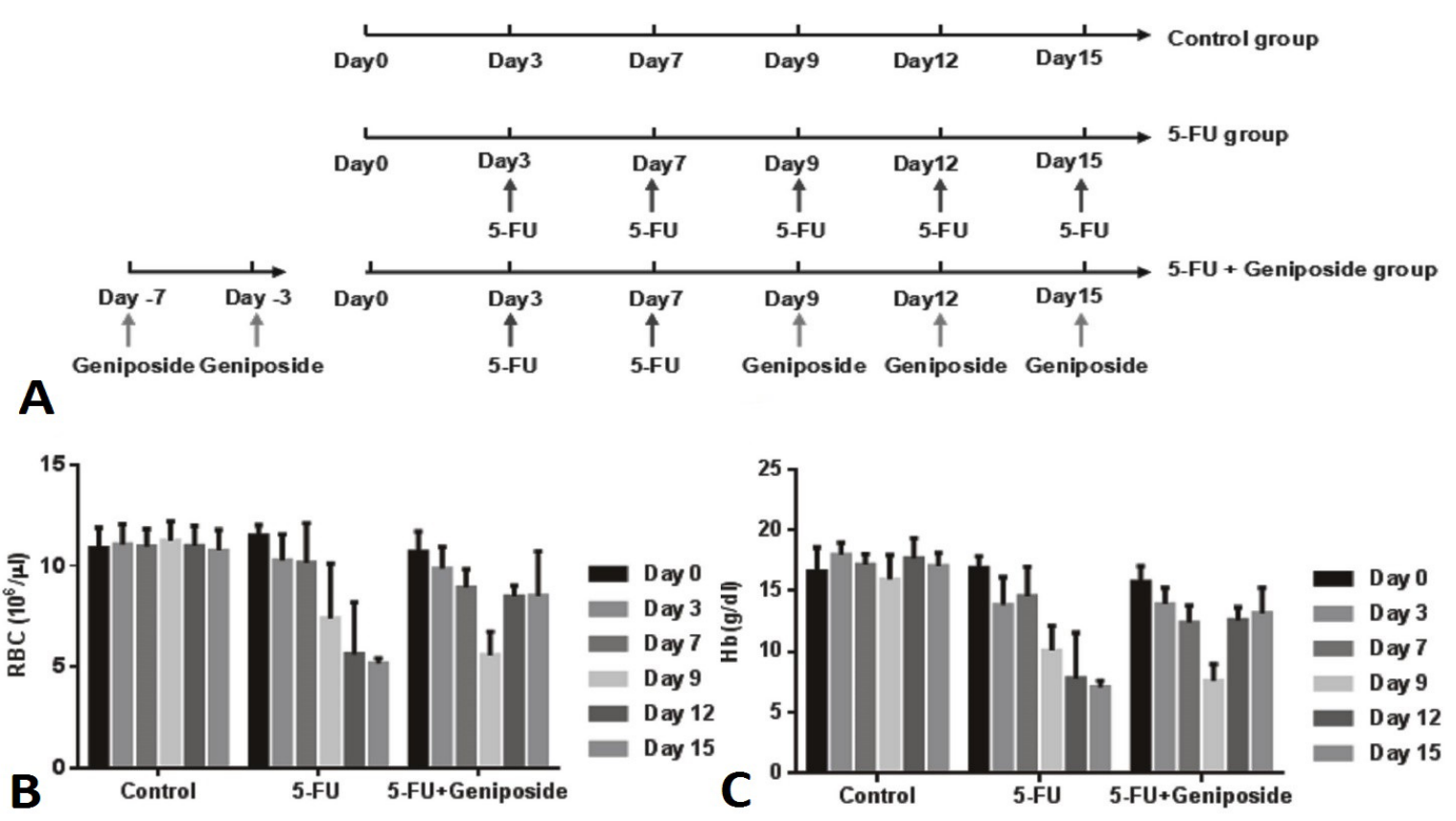

Fig. 2. Evaluation of geniposide condition in mice. (A), schematic representation of the mouse experient design for different time 
point including control group, 5-Fu treatment group and 5-Fu + Geniposide group; $(\mathrm{B}, \mathrm{C})$, parameters of $\mathrm{PB}$ were summarized from control group, 5-Fu treatment group and 5-Fu + Geniposide group mice: $\mathrm{RBC}$ count (B) and $\mathrm{Hb}(\mathrm{C})$.
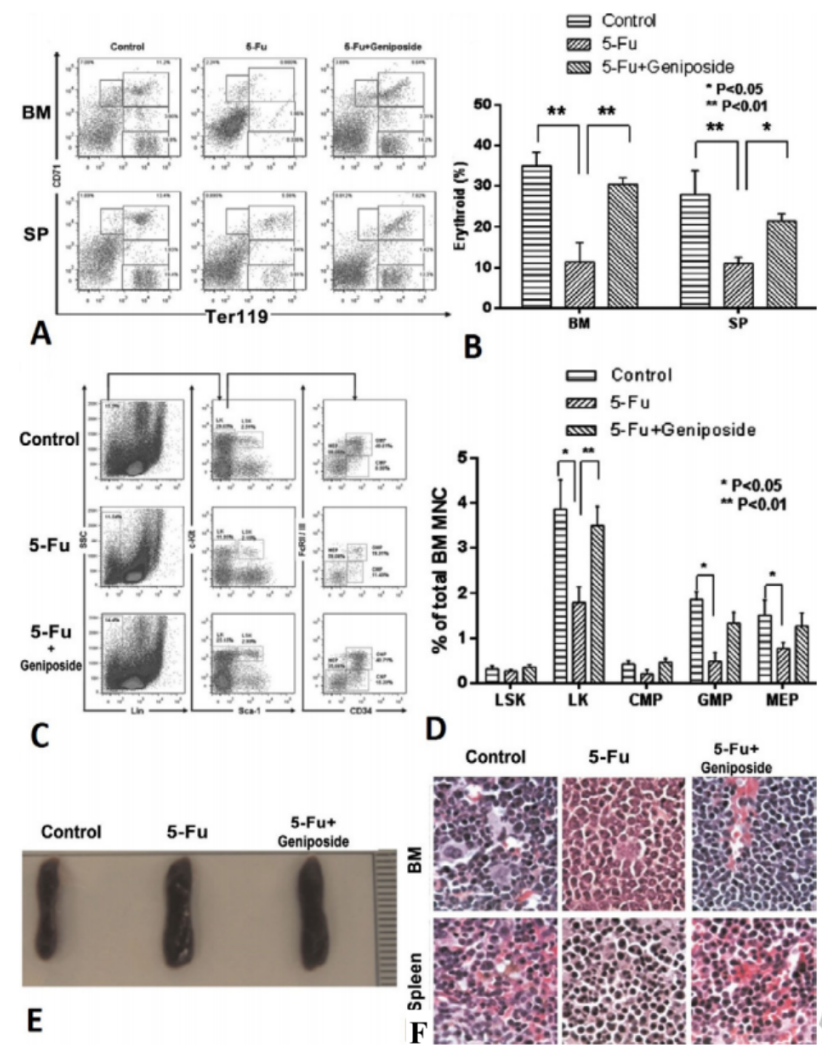

Fig. 3. Evaluation of erythroid cells, LSK / LK cells in mouse BM and spleen. (A), flow cytometry analysis erythroid cells population of $\mathrm{BM}$ and spleen cells of representative in control group, 5-Fu treatment group and $5-\mathrm{Fu}+$ Geniposide group mice; (B), quantitation of the percent of erythroid cells in total BM cells of each group mice; (C), flow cytometric analysis of LSK and LK compartments in BM of control group, 5-Fu treatment group and 5-Fu + Geniposide group mice; (D), quantitation of the percent of LSK, LK, CMP, GMP, and MEP cells in total BM cells of each group mice; (E), spleen size compare for including control group, 5-Fu treatment group and 5-Fu + Geniposide group; (F), H\&E staining of paraffin-embedded sections of BM and spleen for control group, 5-Fu treatment group and 5-Fu + Geniposide group.

\section{Effects of geniposide on the protein level of bone mar- row $(B M)$, and spleen}

To further understand the effect of geniposide on erythropoiesis, BM protein expression was performed. Anti-PI3K, PI3K Phosphorylation antibody (p-PI3K), anti-Akt, Akt phosphorylation antibody (p-Akt) were used to check whether 5-FU up-regulates the expression of Akt phosphorylation (Phosph-Akt) in PB and spleen of different mouse, control and expermintal groups. We also compared the PI3K and p-PI3K expression in different group (Fig. 4). At present, it is not clear whether these molecules are red blood cell production regulators, but their expression levels can be significantly affected by geniposide.
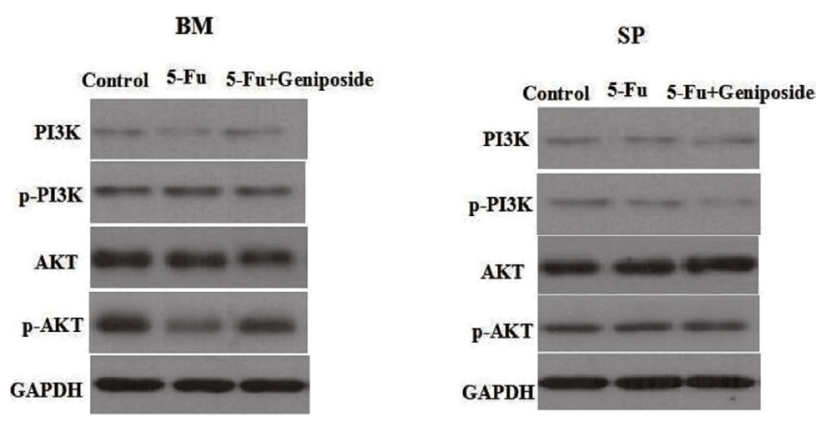

Fig. 4. Effects of geniposide after treatment with 5-Fu. Western blot assay showed in the BM that, the p-Akt expressions had lower expressions in 5-Fu treatment group compared with control group. The low expressions rescued by add Geniposide in 5-Fu + Geniposide group. In spleen, there is no significant difference.

\section{DISCUSSION}

We know that EPO regulates erythropoiesis, and other regulatory factors including cytokines, soluble factors, cell-cell interactions, and cell-extracellular matrix in bone marrow microenvironment also play a regulatory role in erythrocyte development.

Chemotherapy medications 5-FU affects through suppression of Akt signaling (Shan et al., 2017) and at the same time, the red blood cell count and hemoglobin levels are decreased. However, from the mouse experiment, we observed geniposide will rescue the decrease.

It may have an important stimulating effect on erythropoiesis. Based on the existing study, we found that in vitro erythrocyte differentiation of $\mathrm{CD} 34^{+}$cells was not directly affected by geniposide (Fig. 1). We hypothesize that geniposide would be active in vivo, possibly because of the presence of unknown cells or soluble factors in the bone marrow microenvironment. We investigated several possibilities that BM cells might be responsible for the effect of geniposide on erythropoiesis as an unknown mediator. We applied 5-FU to inhibit the ability of CD34+ cells to produce CD71 / Ter119 cells. This reduced effect on erythrocyte differentiation is also associated with the protection of proliferation and maintenance of $\mathrm{CD} 34^{+}$cell phenotypes. The ability of $\mathrm{CD} 34^{+}$cells to maintain the 
protohematopoietic cell phenotype and reduced erythrocyte differentiation has been reported also by others (Wang et al., 2017; Zhang et al., 2017). These results suggest that except for the increased signals, the decreased signals also are the very important regulators for erythropoiesis within the bone marrow microenvironment.

Flow cytometric analysis of bone marrow and spleen cells by the erythroid marker CD71/Ter119, we found that CD71/Ter119 expression decreased in 5-FU treatment group compared with control group. The addition of geniposide (5-FU + geniposide group) reversed this reaction. At the same time, we found that the progenitor cell population ( $\mathrm{Lin}^{-} \mathrm{c}-\mathrm{Kit}^{+}$) decreased in 5-FU group $\mathrm{BM}$, compared with the control group. The population is increased in 5-FU + geniposide group. This indicate that the geniposide works in both bone marrow cells and somatic cells, and geniposide influences bone marrow progenitor cells.

5-FU has a variety of effects, but mainly as a thymidine synthase (TS) inhibitor, it blocks the synthesis of pyrimidine thymidine, a nucleoside necessary for DNA replication (Longley et al., 2003). But we also know that 5-FU anti-tumor effects through suppression of Akt signaling (Zhang et al., 2017). Western blotting results show decreased phospho-Akt expression in the bone marrow cells of 5-FU group, but the phospho-Akt expression was recovered in the $5-\mathrm{FU}+$ geniposide group. The results reveal that 5-FU suppresses the phospho-Akt, and geniposide rescues this reaction in vivo (Fig. 5).

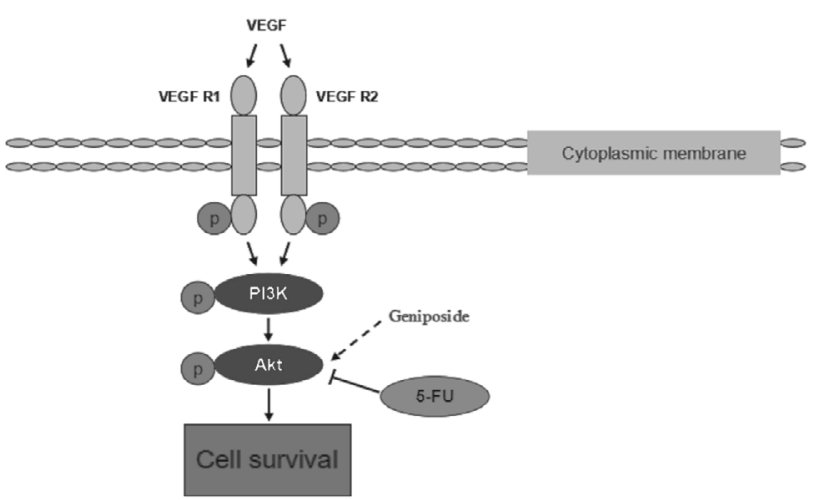

Fig. 5. The hypothesis schematic representation of the potential mechanisms underlying geniposide effects on cell survival.

\section{CONCLUSIONS}

Collectively, our results demonstrate that geniposide does not affect in vitro erythroid differentiation, but it will rescue phospho-Akt expression that is suppressed by
5-FU in vivo, thus subsequently leading to cell survival. This response occurs during the progenitor cell stage of the bone marrow and continues to affect the production of red blood cells. This may be a new potential drug for the treatment of anemia caused by using the chemotherapy drugs.

\section{ACKNOWLEDGEMENTS}

The study was supported by High-level fund projects Changchun University of Chinese Medicine (2018); Jilin Provincial Department of Education " $13^{\text {th }}$ Five-Year" Science and Technology Project (JJKH20170718KJ); Jilin provincial science and technology development project "research and development of coptis paste health care products" (20190304091YY); Jilin province traditional Chinese medicine science and technology project: "preliminary study on the compatibility rule of anti-depression effect of zhizigu decoction" (2018DZ08) and Jilin Provincial Department of Education project (JJKH20170725KJ).

Statement of conflict of interest

The author states that there is no conflict of interest in this article.

\section{REFERENCES}

Carmeliet, P., 2005. Angiogenesis in life, disease and medicine. Nature, 438: 932-936. https://doi. org/10.1038/nature04478

Chan, T.S., Hsu, C.C., Pai, V.C., Liao, W.Y., Huang, S.S., Tan, K.T., Ades, M., Hsu, S.C., Chen, W.Y., Shan, Y.X., Li, C.R., Lee, M.T.L., Jiang, K.Y., Chu, J.M., Lien, G.S., Weaver, V.M. and Tsai, K.K., 2013. Metronomic chemotherapy prevents therapyinduced stromal activation and induction of tumorinitiating cells. J. exp. Med., 13: 2967-2988. https:// doi.org/10.1084/jem.20151665

Chen, J., Peterson, K.R., Iancu-Rubin, C. and Bieker, J.J., 2010. Design of embedded chimeric peptide nucleic acids that efficiently enter and accurately reactivate gene expression in vivo. Proc. natl. Acad. Sci. USA, 107: 16846-16851. https://doi. org/10.1073/pnas.0912896107

Chen, L., Jiang, H. and Gao, W., 2016. Combination with intravenous iron supplementation or doubling erythropoietin dose for patients with chemotherapyinduced anaemia inadequately responsive to initial erythropoietin treatment alone: Study protocol for a randomised controlled trial. Br. med. J. Open., 10: e012231. https://doi.org/10.1136/ bmjopen-2016-012231 
Chen, S., Zhao, X., Sun, P., Qian, J., Shi, Y. and Wang, R., 2017. Preventive effect of Gardenia jasminoides on $\mathrm{HCl} /$ ethanol induced gastric injury in mice. J. pharmacol. Sci., 133: 1-8. https://doi. org/10.1016/j.jphs.2016.05.011

Dall, G.V., Vieusseux, J.L., Korach, K.S., Arao, Y., Hewitt, S.C., Hamilton, K.J., Dzierzak, E., Boon, W.C., Simpson, E.R., Ramsay, R.G., Stein, T., Morris, J.S., Anderson, R.L., Risbridger, G.P. and Britt, K.L., 2017. SCA-1 labels a subset of estrogen-responsive bipotential repopulating cells within the CD24+ CD49fhi mammary stem cellenriched compartment. Stem Cell Rep., 8: 417-431. https://doi.org/10.1016/j.stemcr.2016.12.022

Davila, M.L., 2006. Neutropenic enterocolitis. Curr. Opin. Gastroenterol., 22: 44-47.

Folkman, J., 2007. Angiogenesis: An organizing principle for drug discovery? Nature, 6: 273-286. https://doi.org/10.1038/nrd2115

Henry, D.H., 2006. The role of intravenous iron in cancer-related anemia. Oncology, 20: 21-24.

Kensara, O.A., El-Shemi, A.G., Mohamed,A.M., Refaat, B., Idris, S. and Ahmad, J., 2016. Thymoquinone subdues tumor growth and potentiates the chemopreventive effect of 5-fluorouracil on the early stages of colorectal carcinogenesis in rats. Drug Des. Devel. Ther., 10: 2239-2253. https://doi. org/10.2147/DDDT.S109721

Lazar-Karsten, P., Dorn, I., Meyer, G., Lindner, U., Driller, B. and Schlenke, P., 2011. The influence of extracellular matrix proteins and mesenchymal stem cells on erythropoietic cell maturation. Vox Sang., 101: 65-76. https://doi.org/10.1111/j.14230410.2010.01453.x

Longley, D.B., Harkin, D.P. and Johnston, P.G., 2003. 5-fluorouracil: Mechanisms of action and clinical strategies. Nat. Rev. Cancer, 3: 330-338. https:// doi.org/10.1038/nrc1074

Ma, J., Sawai, H., Ochi, N., Matsuo, Y., Xu, D., Yasuda, A., Takahashi, H., Wakasugi, T. and Takeyama, H., 2009. PTEN regulate angiogenesis through PI3K/ Akt/VEGF signaling pathway in human pancreatic cancer cells. Mol. Cell Biochem., 331: 161-171. https://doi.org/10.1007/s11010-009-0154-x

Meng, S.X., Peng, J.H., Feng, Q., Cao, J.M., and Hu, Y.Y., 2013. The role of genipin and geniposide in liver diseases: A Review. Altern. Integr. Med., 2: 117.
Pirker, R., Pirolli, M., Quigley, J., Hulnick, S., Legg, J., Collins, H. and Vansteenkiste, J., 2013. Hemoglobin decline in cancer patients receiving chemotherapy without an erythropoiesis-stimulating agent. Support Care Cancer, 21: 987-992. https://doi. org/10.1007/s00520-012-1617-2

Pronk, C.J., Rossi, D.J., Maånsson, R., Attema, J.L., Norddahl, G.L., Chan, C.K., Sigvardsson, M., Weissman, I.L. and Bryder, D., 2007. Elucidation of the phenotypic, functional, and molecular topography of a myeloerythroid progenitor cell hierarchy. Cell Stem Cell. , 1: 428-442. https://doi. org/10.1016/j.stem.2007.07.005

Rodgers, G.M., Becker, P.S., Bennett, C.L., Cella, D., Chanan-Khan, A., Chesney, C., Cleeland, C., Coccia, P.F., Djulbegovic, B., Garst, J.L., Gilreath, J.A., Kraut, E.H., Lin, W.C., Matulonis, U., Millenson, M., Reinke, D., Rosenthal, J., Sabbatini, P., Schwartz, R.N., Stein, R.S. and Vij, R., 2008. Cancer- and chemotherapy-induced anemia. $J$. Natl. Compreh. Cancer Network, 10: 628-653. https://doi.org/10.6004/jnccn.2012.0064

Shan, M.Q., Yu, S. and Yan, H., 2017. A review on the phytochemistry, pharmacology, pharmacokinetics and toxicology of geniposide, a natural product. Molecules, 10:1689. https://doi.org/10.3390/ molecules22101689

Walenda, T., Bork, S., Horn, P., Wein, F., Saffrich, R., Diehlmann, A., Eckstein, V., Ho, A.D. and Wagner, W., 2010. Co-culture with mesenchymal stromal cells increases proliferation and maintenance of haematopoietic progenitor cells. J. Cell mol. Med., 14: 337-350. https://doi.org/10.1111/j.15824934.2009.00776.x

Wang, R., Wu, H., Chen, J., Li, S.P., Dai, L., Zhang, Z.R. and, Wang, W.Y., 2017. Anti-inflammation effects and mechanisms study of geniposide on rats with collagen-induced arthritis. Phytother. Res., 31: 631-637. https://doi.org/10.1002/ptr.5775

Zhang, P., Lai, Z.L., Chen, H.F., Zhang, M., Wang, A., Jia, T., Sun, W.Q., Zhu, X.M., Chen, X.F., Zhao, Z. and Zhang, J., 2017. Curcumin synergizes with 5-fluorouracil by impairing AMPK/ULK1dependent autophagy, AKT activity and enhancing apoptosis in colon cancer cells with tumor growth inhibition in xenograft mice. J. exp. clin. Cancer Res., 36: 190-201. https://doi.org/10.1186/s13046017-0661-7 